\title{
Characteristics of the seasonal cycle of surface layer salinity in the global ocean
}

\author{
F. M. Bingham ${ }^{1}$, G. R. Foltz ${ }^{2}$, and M. J. McPhaden ${ }^{3}$ \\ ${ }^{1}$ Center for Marine Science, University of North Carolina Wilmington, 601 S. College Rd., Wilmington, \\ NC 28403-5928, USA \\ ${ }^{2}$ NOAA/Atlantic Oceanographic and Meteorological Laboratory 4301 Rickenbacker Cswy Miami, FL 33149, USA \\ ${ }^{3}$ NOAA / Pacific Marine Environmental Laboratory, 7600 Sand Point Way NE, Seattle, WA 98115, USA
}

Correspondence to: F. M. Bingham (binghamf@uncw.edu)

Received: 20 October 2011 - Published in Ocean Sci. Discuss.: 7 December 2011

Revised: 19 August 2012 - Accepted: 6 September 2012 - Published: 30 October 2012

\begin{abstract}
The seasonal variability of surface layer salinity (SLS), evaporation $(E)$, precipitation $(P), E-P$, advection and vertical entrainment over the global ocean is examined using in situ salinity data, the National Centers for Environmental Prediction's Climate System Forecast Reanalysis and a number of other ancillary data. Seasonal amplitudes and phases are calculated using harmonic analysis and presented in all areas of the open ocean between $60^{\circ} \mathrm{S}$ and $60^{\circ} \mathrm{N}$. Areas with large amplitude SLS seasonal variations include: the intertropical convergence zone (ITCZ) in the Atlantic, Pacific and Indian Oceans; western marginal seas of the Pacific; and the Arabian Sea. The median amplitude in areas that have statistically significant seasonal cycles of SLS is 0.19 . Between about $60^{\circ} \mathrm{S}$ and $60^{\circ} \mathrm{N}, 37 \%$ of the ocean surface has a statistically significant seasonal cycle of SLS and $75 \%$ has a seasonal cycle of $E-P$. Phases of SLS have a bimodal distribution, with most areas in the Northern Hemisphere peaking in SLS in March/April and in the Southern Hemisphere in September/October.

The seasonal cycle is also estimated for surface freshwater forcing using a mixed-layer depth climatology. With the exception of areas near the western boundaries of the North Atlantic and North Pacific, seasonal variability is dominated by precipitation. Surface freshwater forcing also has a bimodal distribution, with peaks in January and July, 1-2 months before the peaks of SLS. Seasonal amplitudes and phases calculated for horizontal advection show it to be important in the tropical oceans. Vertical entrainment, estimated from mixedlayer heaving, is largest in mid and high latitudes, with a seasonal cycle that peaks in late winter.
\end{abstract}

The amplitudes and phases of SLS and surface fluxes compare well in a qualitative sense, suggesting that much of the variability in SLS is due to $E-P$. However, the amplitudes of SLS are somewhat different than would be expected and the peak of SLS comes typically about one month earlier than expected. The differences of the amplitudes of the two quantities is largest in such areas as the Amazon River plume, the Arabian Sea, the ITCZ and the eastern equatorial Pacific and Atlantic.

\section{Introduction}

The salinity of the ocean surface layer (SLS) can be considered a proxy for the impact of the hydrologic cycle, or the flux of freshwater across the air-sea interface. Areas of relatively high SLS tend to be ones where evaporation is a dominant process with a net transport of freshwater from ocean to atmosphere. Conversely, areas of relatively low SLS tend to be ones where precipitation is a dominant process with a net transport of freshwater from the atmosphere to the ocean (Durack and Wijffels, 2010). The use of SLS in understanding the global hydrologic cycle is a major justification for two recent satellite missions to map sea surface salinity (SSS; the distinction between SSS and SLS will be discussed in the next section), NASA's Aquarius (Lagerloef et al., 2008) and ESA's Soil Moisture and Ocean Salinity (SMOS) (Berger et al., 2002).

The atmospheric part of the hydrologic cycle operates on a short time scale compared to the global ocean circulation. 
Typical residence time for water in the atmosphere is on the order of 7 days (Bengtsson, 2010), whereas ocean circulation processes can have time scales of years to decades. The hydrologic cycle is an integral component of weather and climate variability on a local to a global scale. Weather and climate, in turn, are driven by seasonally and latitudinally varying inputs of solar radiation. The most important time scale of variability in weather and climate is the seasonal, where intra-year changes in solar input cause changes in such features as the position of the intertropical convergence zone (ITCZ), paths of mid-latitude storm tracks, monsoon circulation, particularly in the vicinity of east and south Asia, and changes in the temperature and humidity of the air that comes into close contact with the ocean. So in studying the interactions between ocean and atmosphere, we come across a mismatch of time scales, between a rapidly varying (days to months) atmosphere and a slowly varying (years to decades) ocean. The seasonal time scale sits right at the boundary between these scales, and thus makes an important contribution to the freshwater exchanges between atmosphere and ocean.

While SLS varies on many different time and space scales (Tomczak, 1995), here we focus on the seasonal cycle - variability that is phase-locked to the calendar. The global seasonal cycle of SLS has been studied in the past by Boyer and Levitus (2002), who published maps of the amplitude and phase of the seasonal harmonic of SLS based on the 1998 World Ocean Atlas monthly gridded values (Boyer et al., 1998a, b, c). SLS at the seasonal time scale is certainly influenced by surface fluxes (Delcroix and Henin, 1991; Delcroix et al., 1996) and in some areas by other processes such as vertical mixing, entrainment and horizontal advection (Foltz et al., 2004; Foltz and McPhaden, 2008; Johnson et al., 2002). In the tropics, between $10^{\circ} \mathrm{N}$ and $5^{\circ} \mathrm{S}$, the most dominant element of surface forcing at the seasonal scale is precipitation variability associated with meridional migration of the ITCZ (da Silva et al., 1994). Evaporation is the dominant process in winter near the western boundaries, mainly associated with cold air outbreaks (Yu et al., 2008).

There have been many regional efforts to study the seasonal variability of SSS, especially in the tropical oceans, including the Pacific (Delcroix and Henin, 1991; Bingham and Lukas, 1996; Delcroix et al., 1996, 2005; Gouriou and Delcroix, 2002), Atlantic (Dessier and Donguy, 1994; Reverdin et al., 2007; Foltz and McPhaden, 2008) and Indian (Rao and Sivakumar, 2003). Rao and Sivakumar, for example, show maps of annual average SSS, annual variance, maps for each month, and amplitude and phase of the annual cycle. In the Arabian Sea and Bay of Bengal, they show large seasonal amplitudes of up to 0.7 and quite large variability in the phase. Ren and Riser (2009) studied the seasonal balance of mixed-layer salinity in a region of the northeastern subarctic Pacific. They found the mixed-layer salinity is maximum in spring, with an amplitude of about 0.2. Precipitation, evaporation, advection and entrainment all played a role in the seasonal balance. Foltz and McPhaden (2008) looked at the seasonal variability of SSS in three regions in the Atlantic, one in the central North Atlantic with a weak seasonal cycle and two in the tropical Atlantic and western North Atlantic with stronger ones.

Bingham et al. (2010; henceforth BFM) examined the seasonal cycle of SLS in the Pacific Ocean between $40^{\circ} \mathrm{S}$ and $60^{\circ} \mathrm{N}$. They found areas with large seasonal variation in the northern tropical Pacific, under the ITCZ, along the western and northern boundary of the North Pacific, and in the central South Pacific loosely centered around $10^{\circ} \mathrm{S}$. They compared these variations to the corresponding atmospheric fluxes of evaporation $(E)$, precipitation $(P)$, and $E-P$. They also examined one of the advection terms and the entrainment term in the equation for SSS evolution and found them to be important in limited areas. The overall impression is that seasonal variations in SLS, where present, are mainly driven by seasonal variations in $E-P$. Even the amplitudes and phases matched in a few closely studied areas. Advection, entrainment and other such processes are important in the overall SLS balance in some areas, but $E-P$ is dominant on seasonal time scales.

This view was tested by Yu (2011), who looked at similar issues as we will here. The paper examined contributions to the seasonal variance from various terms of the surface balance equation, $E-P$ forcing, vertical entrainment and horizontal advection by the mean and seasonally-varying parts of the geostrophic and Ekman surface flow. Yu found that the $E-P$ contribution to the SLS tendency was dominant in large areas of the ocean, but that there were other areas where other terms dominated. In particular, the seasonallyvarying Ekman flow advecting the mean salinity field was important throughout large areas of the global ocean, especially in the subtropics (see Yu, 2011, Fig. 9). One thing Yu does not seem to do in her calculation is to take into account the seasonal variation of the mixed-layer depth, which will be shown here to be an important part of the entrainment term. She also does not present information about the phase of the SLS on a global scale as we will here, nor does she assess the statistical significance of the regression fits.

These previous efforts have been valuable contributions to the literature, but a global view of the seasonal cycle of SLS is called for in more detail than was provided by Boyer and Levitus (2002), Yu (2011) or Roemmich and Gilson (2009). We need to know how well SLS and surface freshwater flux match on a global scale to help us better understand how the global hydrologic cycle influences the global salinity balance. We will therefore describe when and where the seasonal harmonic is important and how the seasonal amplitudes and phases fit into a global picture. We will compare the seasonal variability of SLS to that of evaporation and precipitation to get a sense of the relationship between them. We provide a quantification of the global seasonal cycle of SLS in relation to surface forcing, building on more qualitative previous analyses that were conducted before the Argo era. 


\section{Data}

Salinity values used in this publication are unitless practical salinities based on the practical salinity scale of 1978 (UNESCO, 1981; Valladares et al., 2011). Table 1 shows the URLs where various datasets were accessed.

SLS is defined here as the uppermost salinity measurement in a given profile as long as it is above $10 \mathrm{~m}$, or a single bucket or thermosalinograph measurement. It differs from SSS which can be considered a skin value within $1 \mathrm{~cm}$ of the surface (Henocq et al., 2009; Yu, 2010).

The SLS data come from Argo (http://www.argo.net; Table 1, line 1), the World Ocean Database (Table 1, line 2; Johnson et al., 2009), the Sea Surface Salinity Observation Service (Delcroix et al. 2005; LEGOS; Table 1, line 3) and the Global Surface Underway Data (http://www.gosud.org; GOSUD; Table 1, line 4) project. Argo data are profiling floats. The World Ocean Database is a compendium of historical data collected mainly by research vessels. LEGOS is a program to measure and archive data collected using buckets and thermosalinographs from volunteer observing ships from $30^{\circ} \mathrm{S}$ to $30^{\circ} \mathrm{N}$ during 1950-2003. Following Delcroix et al. (2005), we subtracted 0.1 from each bucket salinity value in the LEGOS dataset. GOSUD data are from thermosalinographs on board specially outfitted commercial vessels. These four data sources were combined and screened for duplicates. As explained in BFM (Sect. 2.1.6), no systematic quality control beyond that of the data providers was carried out due to the disparate nature of the data sources. Our final SLS dataset consists of $1.66 \times 10^{6}$ observations (Fig. 1) between about $60^{\circ} \mathrm{S}$ and $60^{\circ} \mathrm{N}$ (actually $61.25^{\circ} \mathrm{S}$ and $61.25^{\circ} \mathrm{N}$ ). The number of observations increases with time (Fig. 2), with the exception of the mid-1990s, to nearly $100000 \mathrm{yr}^{-1}$ in 2010.

We note that there are many moorings associated with the Indian (RAMA), Pacific (TAO) and Atlantic (PIRATA) tropical arrays. No SLS data from any of these moorings are included here as the purpose of this study is to get a broad spatial view. Data from a similar SLS dataset and some TAO moorings were compared by BFM, who found good agreement in seasonal amplitudes and phases.

Evaporation and precipitation data were obtained from the National Centers for Environmental Prediction's (NCEP) Climate Forecast System Reanalysis (CFSR; Table 1, line 5; Saha et al., 2010). We used the monthly product in the date range January 1979-December 2009. This product is distributed on a $2.5^{\circ} \times 2.5^{\circ}$ grid, which is also the size of the grid in which we did our calculations with the SLS data. A similar analysis was carried out in BFM for the Pacific using different flux products: the OAFlux dataset (Yu et al., 2008) for evaporation and the Global Precipitation Climatology Project (Adler et al., 2003) for precipitation. For the Pacific, the results from BFM (their Figs. 8 and 10) and those presented here are nearly identical. The amplitude and phase of the seasonal cycle computed (by harmonic analysis, see below)

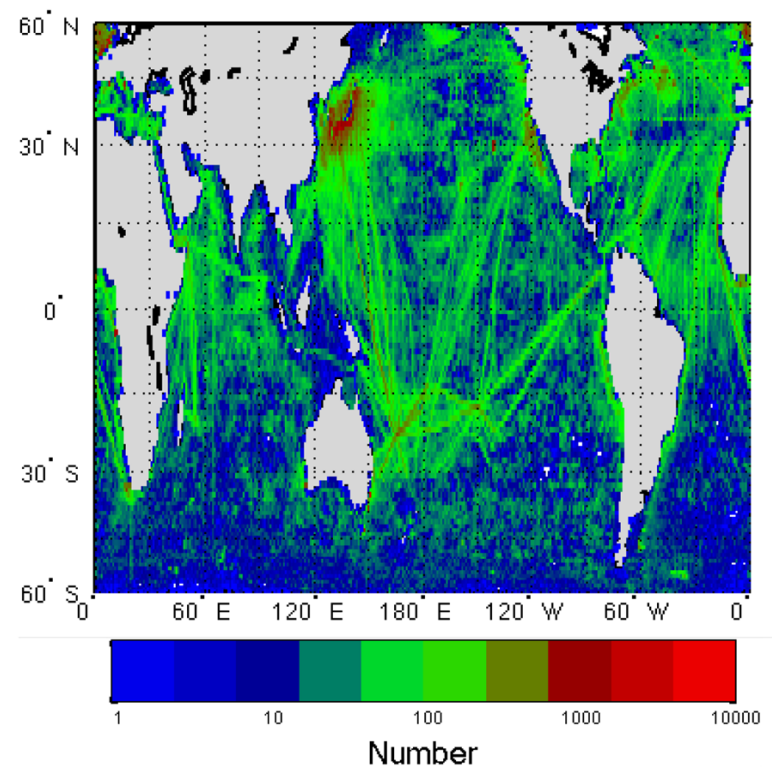

Fig. 1. Distribution of final SLS dataset in number of observations per $1^{\circ} \times 1^{\circ}$ square. Note this is the distribution of the final dataset after screening for duplicates.

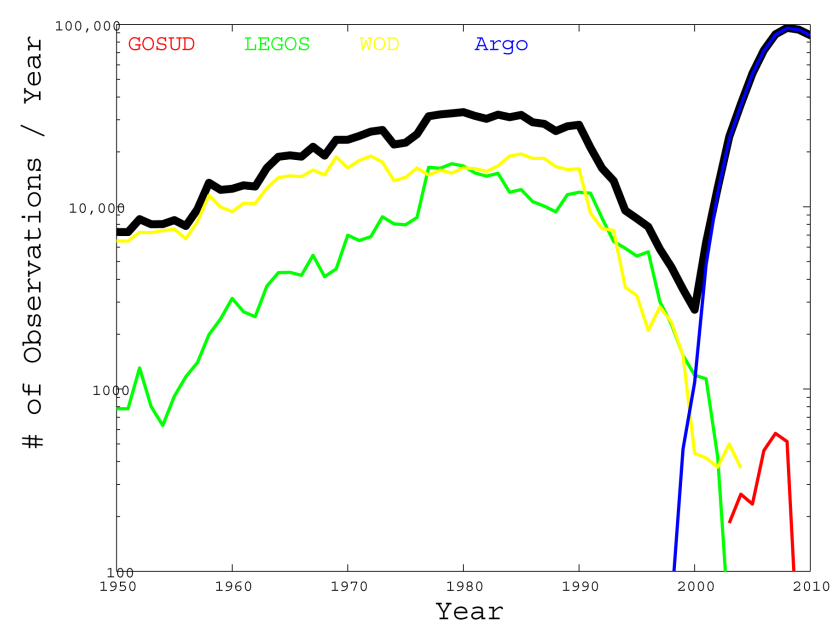

Fig. 2. Distribution of final SLS dataset by time. Colors of lines indicate different datasets as matched with colored text in the upper part of the figure. Dark black line is the total number of observations. Note this is the distribution of the final dataset after screening for duplicates. Note also the y-axis is logarithmic.

from these two datasets were compared by scatter plot (not shown) with those from the CFSR. Most points fell close to a one-to-one correspondence line, indicating that the results we will show do not depend very sensitively on which of these flux products is used.

The mixed-layer depth climatology we used was derived from the World Ocean Database by deBoyer Montegut et al. (2004) (Table 1, line 6). It uses a temperature criterion of $0.2^{\circ} \mathrm{C}$ difference from $10 \mathrm{~m}$ depth to estimate the mixed-layer 
Table 1.

\begin{tabular}{|c|c|c|c|}
\hline & Dataset name & URL accessed from & $\begin{array}{l}\text { Date of most recent } \\
\text { observation used } \\
\text { in this paper }\end{array}$ \\
\hline 1 & Argo & http://www.nodc.noaa.gov/argo/basins_data.htm & August 2011 \\
\hline 2 & World Ocean Database & http://www.nodc.noaa.gov/OC5/WOD/pr_wod.html & December 2004 \\
\hline 3 & LEGOS & http://www.legos.obs-mip.fr/en/observations/sss/datadelivery/products/ & July 2003 \\
\hline 4 & GOSUD & http://www.gosud.org/Data-delivery/FTP-access & March 2009 \\
\hline 5 & NCEP CFSR & http://dss.ucar.edu/pub/cfsr.html & December 2009 \\
\hline 6 & Ocean Mixed-layer Climatology & http://www.ifremer.fr/cerweb/deboyer/mld & N/A \\
\hline 7 & World Ocean Atlas 2009 & http://www.nodc.noaa.gov/OC5/WOA09/pr_woa09.html & N/A \\
\hline 8 & OSCAR & http://www.oscar.noaa.gov/ & April 2012 \\
\hline 9 & Ekman pumping & http://coastwatch.pfeg.noaa.gov/erddap/griddap/erdQSstress3day.html & April 2012 \\
\hline
\end{tabular}

depth. Note this is not a time series, but a seasonal climatology, with a single value for each month for each $2^{\circ}$ square. The surface forcing term, $S_{0}(E-P) / h$, was calculated from the mixed-layer depth, $E$ and $P$ after interpolating them to a common $2.5^{\circ} \times 2.5^{\circ}$ grid. $S_{0}=35$ is a reference salinity and $h$ is the mixed-layer depth from the climatology.

Besides the SLS tendency and the surface flux, we have further calculated two of the other terms in the seasonal SLS balance. $u^{\prime} \cdot \nabla \bar{S}$ is the seasonal horizontal advection of the mean salinity field (see BFM, Sect. 3.2 for a description of the method). This required use of the OSCAR surface current dataset (Bonjean and Lagerloef, 2002; Table 1, line 8). Also, we calculated the seasonal vertical advection, $w^{\prime} \frac{\partial \bar{S}}{\partial z}$, where $w^{\prime}=w_{E}+\frac{\partial h^{\prime}}{\partial t} \cdot w_{E}$ is the seasonal Ekman pumping term (positive upward), and $h^{\prime}$ is the seasonal mixed-layer depth. This required use of the World Ocean Atlas 2009 (Antonov et al., 2010; Table 1, line 7) salinity profile data to get the vertical gradient of salinity, an Ekman pumping dataset based on QuickSCAT (Table 1, line 9), as well as the deBoyer Montegut et al. (2004) mixed-layer depths. See BFM Sect. 3.2 for more details on the calculations and datasets used. Note that seasonal variations of horizontal and vertical gradients of salinity are not included in the advection calculations because of large uncertainties associated with the calculation of these quantities.

The harmonic analysis we performed is detailed in BFM, Sect. 2.2 (see also Emery and Thomson, 2001). The product is an amplitude and phase for SLS, $E, P, E-P, S_{0}(E-$ $P) / h$, advection and vertical entrainment in each $2.5^{\circ} \times 2.5^{\circ}$ grid box. The phase is expressed in months relative to January 1 of the maximum of each quantity. The amplitude is unitless for SLS, in units of $\mathrm{kg} \mathrm{m}^{-2} \mathrm{~s}^{-1}$ for $E, P$ and $E-P$, and $\mathrm{s}^{-1}$ (or pss s${ }^{-1}$ ) for $S_{0}(E-P) / h$, advection and entrainment. $S_{0}(E-P) / h$ was converted to units of $\mathrm{s}^{-1}$ by division of $(E-P)$ by the density of pure water, $1000 \mathrm{~kg} \mathrm{~m}^{-3}$. Note $1.0 \times 10^{-4} \mathrm{~kg} \mathrm{~m}^{-2} \mathrm{~s}^{-1}$ is equivalent to $320 \mathrm{~cm} \mathrm{yr}^{-1}$ of freshwater evaporation or precipitation. Since the amplitudes and phases were obtained using a common multivariate linear least squares procedure, the statistical significance could be easily evaluated using a standard F-test (e.g., Emery and Thomson, 2001). Fits were considered statistically significant if they were at or above the $95 \%$ level.

\section{Results}

Global values of SLS amplitude, phase and percent of variance are presented in Figs. 3, 4 and 5. Figs. 3 and 4 are similar to a figure published by Boyer and Levitus (2002; their Fig. 3). The additional information here is that in areas where the harmonic fit is not statistically significant no value is shown. Further, the harmonics here are obtained not from a gridded climatology, but from the observations themselves.

Areas having large amplitudes cluster in several regions: along $10^{\circ} \mathrm{N}$ and $5-10^{\circ} \mathrm{S}$ in the Atlantic, Pacific and Indian Oceans; western Pacific marginal seas including the Indonesian Archipelago, South China Sea and Sea of Japan; and the eastern boundary regions of the Pacific and Atlantic equatorial oceans. The western and northern boundaries of the North Pacific, and to a lesser extent the North Atlantic, contain a very large area with weak but statistically significant seasonal cycles. There are large areas of the global ocean with no consistent seasonal cycle at all: most areas of the Southern Hemisphere below $20^{\circ} \mathrm{S}$ including the Southern Ocean, and much of the central North Pacific and North Atlantic. If one calculates the actual surface area for each $2.5^{\circ} \times 2.5^{\circ}$ square, and figures out which ones have a statistically significant seasonal cycle, it amounts to about $37 \%$ of the ocean surface between $60^{\circ} \mathrm{S}$ and $60^{\circ} \mathrm{N}$, or $1.1 \times 10^{8} \mathrm{~km}^{2}$.

The phase of the seasonal cycle shows consistent behavior across ocean basins (Fig. 4). The large bands across $10^{\circ} \mathrm{N}$ and $5-10^{\circ} \mathrm{S}$ have maximum SLS in each hemisphere's respective late spring, with the exception of the Arabian Sea where it is maximum in mid-summer. The western boundary areas in the North Pacific and North Atlantic are maximum in late winter. The percentage of variance (Fig. 5) indicates that the seasonal cycle accounts for a large fraction of the variance in the off-equatorial bands, particularly the ones in the Northern Hemisphere. Elsewhere, the percentage of variance 


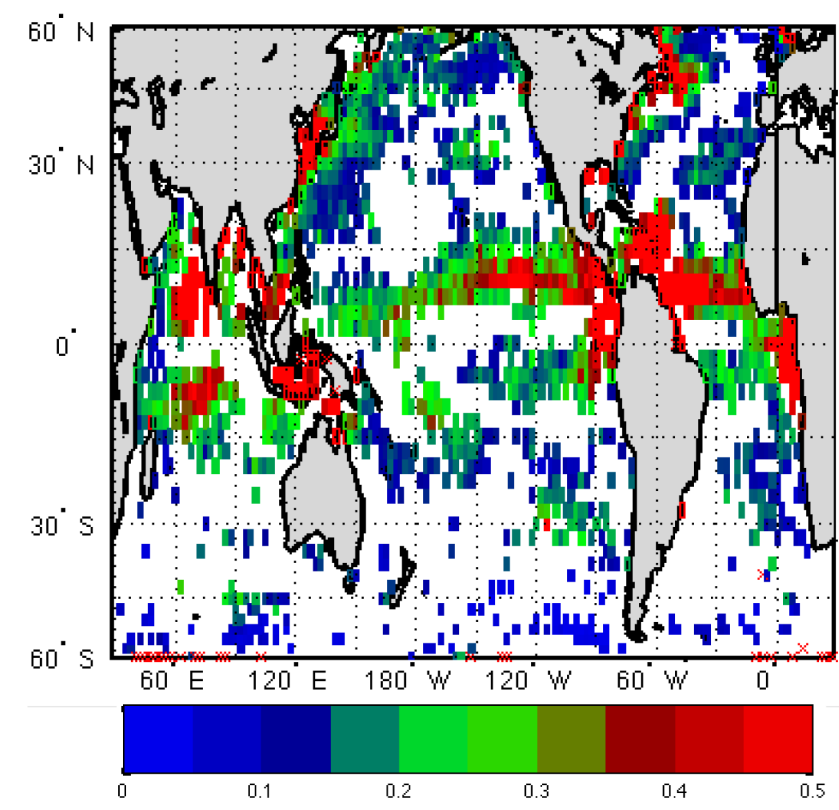

Fig. 3. Amplitude (unitless practical salinity) of the seasonal cycle of SLS in $2.5^{\circ} \times 2.5^{\circ}$ squares. Ocean areas with no color had sufficient observations, but were found to have no statistically significant seasonal cycle using a standard statistical test (see text for details). Areas with a red "x" have fewer than 10 observations. The scale indicates the numerical values associated with each color.

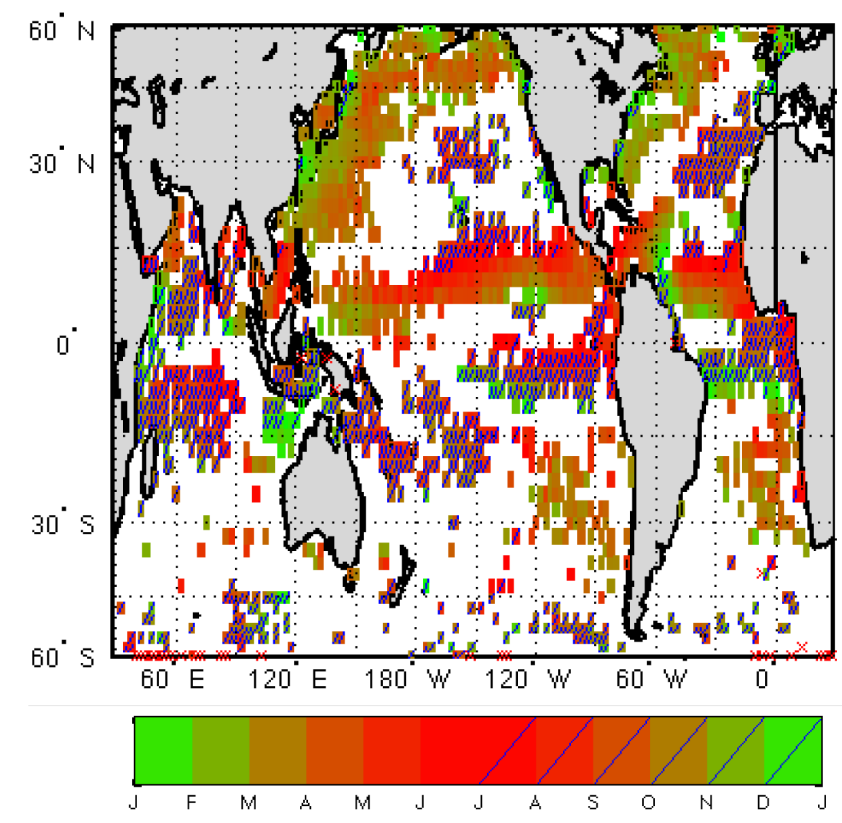

Fig. 4. As in Fig. 3, for phase (in months) indicating month of maximum SLS in each $2.5^{\circ} \times 2.5^{\circ}$ square.

is mostly smaller, with the exception of the Pacific marginal seas, and particularly the Indonesian seas where it reaches $60-80 \%$ of the variance.

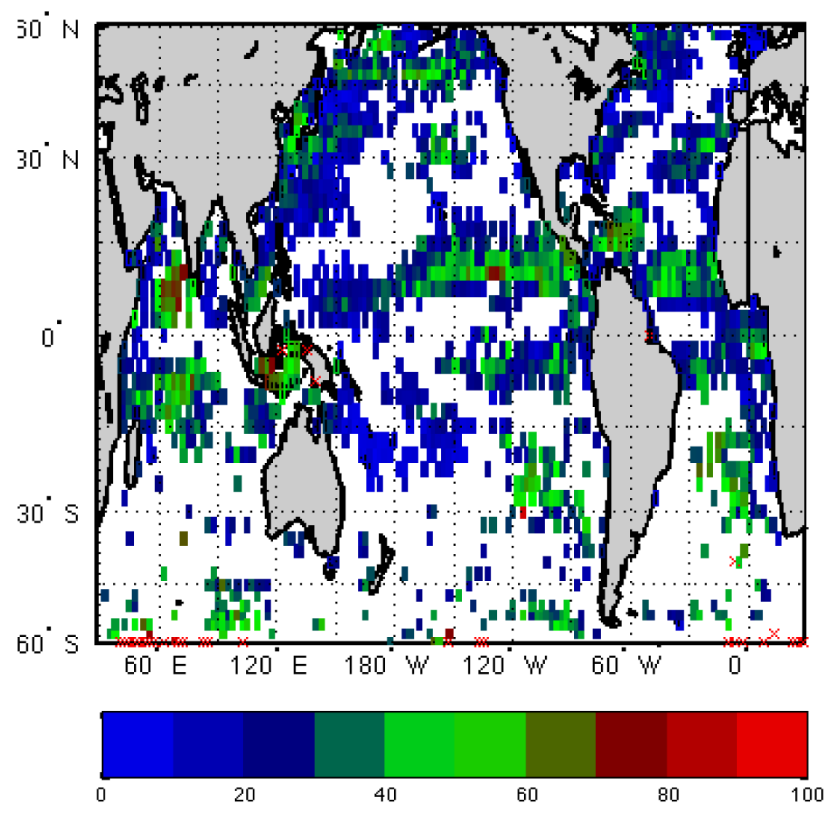

Fig. 5. As in Fig. 3, for R-squared (in \%).

Seasonal horizontal advection of SLS (Fig. 6) indicates that this term is important mainly in the tropics, and in particular north of the equator. Large amplitudes are seen in the eastern tropical Pacific near the coast of Central America and in the western tropical Atlantic near the Amazon outflow. The tropical Indian Ocean has large amplitudes as well from $15^{\circ} \mathrm{S}$ north to the Asian continent. The phase of this term shows a lot of variability and no real pattern to it.

Vertical advection or entrainment plays a larger role off the equator (Fig. 7). The largest element in this term is the seasonal heaving of the mixed-layer, $\frac{\partial h^{\prime}}{\partial t} \frac{\partial \bar{S}}{\partial z}$. The seasonal cycle of the Ekman pumping was found to be small relative to the mixed-layer heaving, possibly a feature of the particular dataset used (Table 1, line 9) (the version of this figure from BFM, their Fig. 11, is probably incorrect due to an error in the calculation). This term is minimum (i.e., tending to decrease SLS) in the winter and spring (displayed in Fig. 7b as a maximum in the negative of the term) throughout the higher latitudes of both hemispheres as the surface layer entrains fresher water from the interior below. It also increases with increasing latitude in the Northern Hemisphere.

A simplified view of the balance of SLS is between SLS tendency, surface forcing, horizontal advection and vertical entrainment (Delcroix et al., 1996), i.e.,

$$
\frac{\partial S}{\partial t}=\frac{S_{0}(E-P)}{h}-u \cdot \nabla \bar{S}-w^{\prime} \frac{\partial \bar{S}}{\partial z} .
$$

We now examine the geographical distribution of the first two terms of this equation, the SLS tendency and surface forcing.

If each individual $2.5^{\circ} \times 2.5^{\circ}$ square is considered as an observation, then we can aggregate the observations to get 

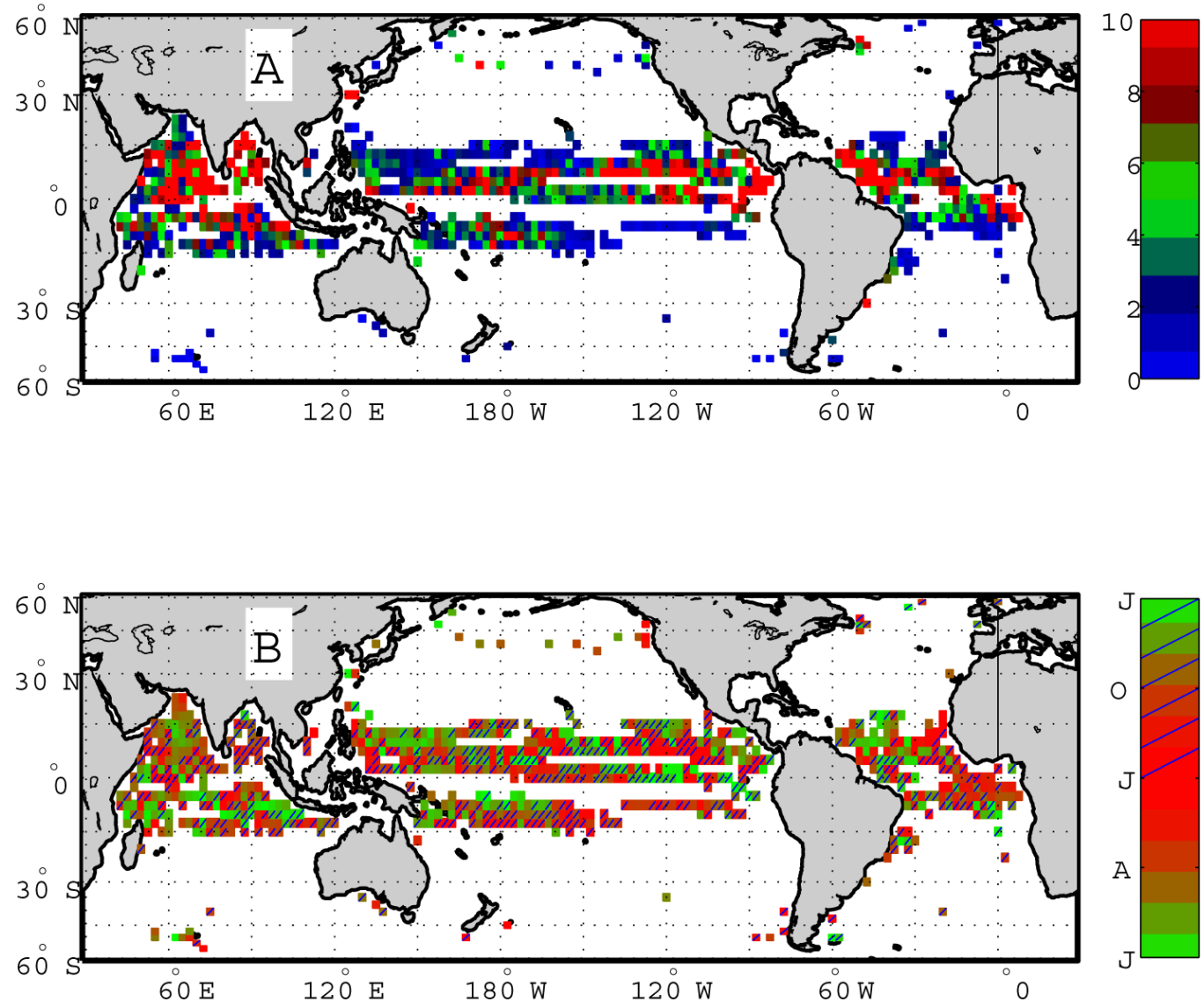

Fig. 6. Geographical distribution of the (A) amplitude and (B) phase of the negative of the horizontal advection term, $-u^{\prime} \cdot \nabla(\bar{S})$. Color bars at right indicate scales. Amplitudes are in units of $10^{-8} \mathrm{~s}^{-1}$. Phases are in months.

a sense of the global distribution of the seasonal cycle of SLS. Figures 8 and 9 display the distribution of the seasonal cycle amplitude and phase (blue bars). The amplitude peaks at $0.1-0.2$, with the majority of areas below 0.5 . The phase has a remarkable two-peaked distribution (Fig. 9). Most squares have maximum SLS in either March/April or September/October, with relatively few having maxima in December and July. Looking at the horizontal bars in Figs. 8 and 9 gives a sense of how the amplitude and phase is distributed by hemisphere. The peak in March/April is almost entirely determined by processes occurring in the Northern Hemisphere, whereas the one in September/October is mostly associated with the Southern Hemisphere. While the small amplitude seasonal cycles occur in both hemispheres, the large amplitude ones occur mostly in the Northern (Fig. 8).

We did a calculation of frequency distribution of SLS phase and amplitude as shown in Figs. 8 and 9, only using total surface area instead of the simple number of $2.5^{\circ} \times 2.5^{\circ}$ squares. The total area of a $2.5^{\circ} \times 2.5^{\circ}$ square changes as a function of latitude, and we wanted to make sure that this was not a major factor. The results are not shown here as they were very similar to the results we do show in Figs. 8 and 9.

Examining the Northern Hemisphere more closely (Fig. 10), we can see the distribution of phase by latitude. The March/April peak is mainly determined by processes in the $30-60^{\circ} \mathrm{N}$ range, while the lower latitudes peak about a month later in April/May. The September/October peak is exclusively a result of the $20-40^{\circ} \mathrm{N}$ latitude range, in particular the region centered at $30^{\circ} \mathrm{N}, 150^{\circ} \mathrm{W}$ (Fig. 3).

The seasonal cycles of $E, P, E-P$ (Fig. 11) and $S_{0}(E-$ $P) / h$ (Fig. 12) show many areas with statistically significant seasonal cycles where there are none for SLS (Fig. 3). The evaporation (Fig. 11c, d) has large amplitudes in the western boundary regions of the North Pacific and North Atlantic, and relatively small but consistent values elsewhere. The precipitation (Fig. 11e, f) has areas of activity under the ITCZ in the Atlantic and Pacific, in the western boundary region of the low latitude North Pacific (but not so much in the North Atlantic), in the Indonesian seas and in the Arabian Sea (Fig. 11e and $f$ are similar to Adler et al., 2003; their Fig. 15). When $E$ and $P$ are combined into $E-P$ (Fig. 11a, b), the result takes on most of the characteristics of $P$, except in 

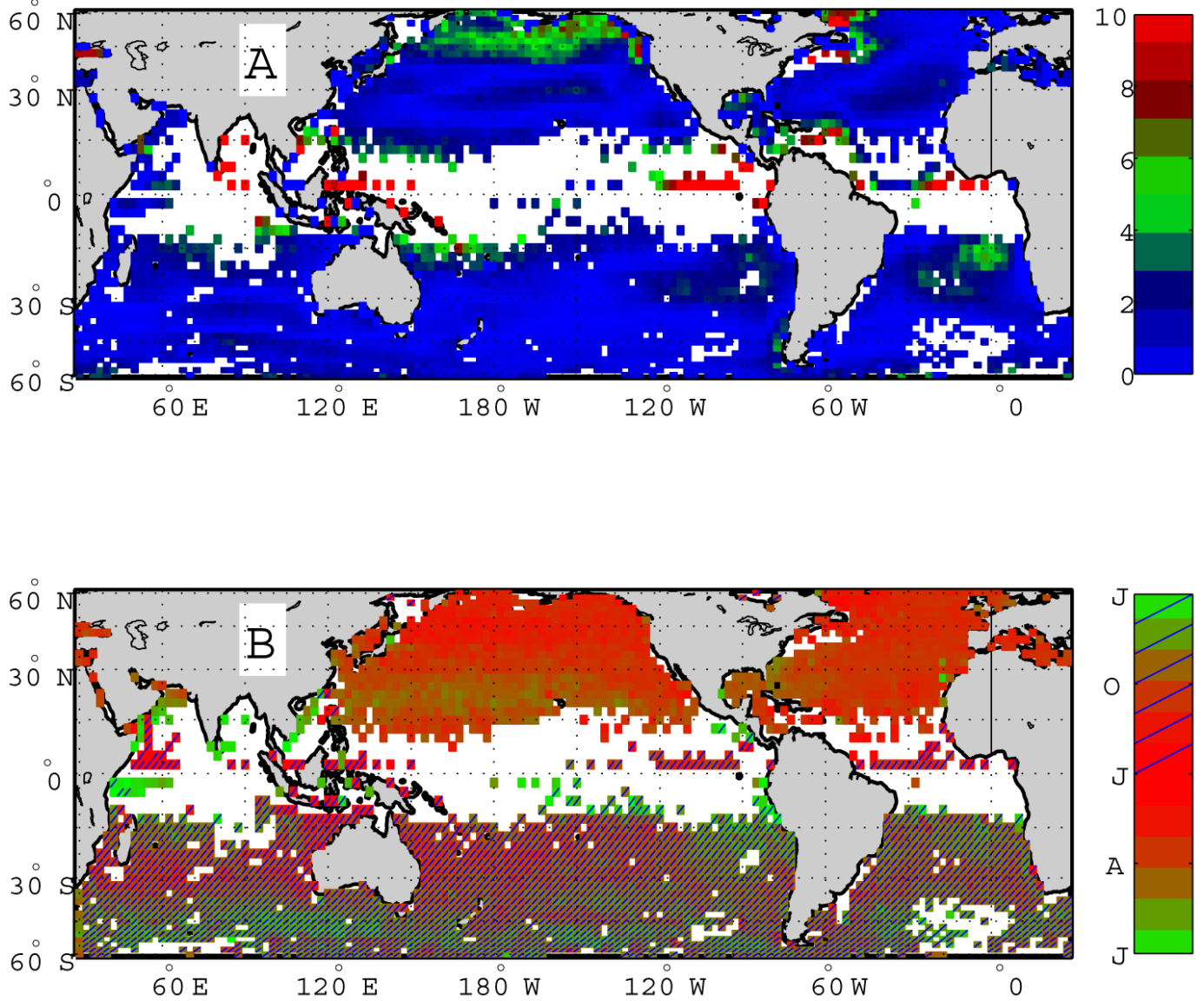

Fig. 7. As in Fig. 6, but for the negative of the vertical advection, $-w^{\prime} \frac{\partial \bar{S}}{\partial z}$.

the western North Pacific and North Atlantic. In other words, in the areas of the ocean where there are seasonal cycles of $E-P$, they are mostly a result of $P$, with a couple of smaller areas associated with $E$. Finally, the term $S_{0}(E-P) / h$, the surface forcing term in the salinity balance equation, is similar in distribution to $E-P$ (Fig. 11a, b). The Northern Hemisphere western boundary regions, particularly in the North Pacific, appear as hot spots in amplitude. Large areas of the Southern Hemisphere oceans have no seasonal cycle of this term. The Southern Hemisphere western boundary regions have no counterpart to the Northern Hemisphere's, giving the impression of a Southern Hemisphere that is far less seasonal than the Northern. In the western boundary and ITCZ regions of the North Pacific and Atlantic, the seasonal amplitude of $S_{0}(E-P) / h$ is much larger than that of vertical advection. However, northward of $45^{\circ} \mathrm{N}$ and in the interior North Pacific and Atlantic, vertical advection is comparable in magnitude.

We have done the calculation of the seasonal cycle of $S_{0}(E-P) / h$ (Fig. 12) using constant values of $E, P$ and $E-P$ to see what the effect of mixed-layer depth variation is in this calculation. We do not show these calculations here.
Despite large seasonal variability of the mixed-layer depth throughout the ocean, it has little effect on the geographical distribution of amplitude and phase depicted in Fig. 12 because the seasonal amplitude of the mixed-layer depth does not vary geographically nearly as much as that of $E$ and $P$.

Taking Figs. 12 and 3 and 4, we can get some insight into the details of the relationship between $S_{0}(E-P) / h$ and SLS. First, we take all the $2.5^{\circ} \times 2.5^{\circ}$ squares depicted in Figs. 3 and 12 and extract only those squares where there is also a statistically significant value in both. We then do a scatter plot of amplitude (Fig. 13) and phase (Fig. 14) comparing the two. For the amplitude, generally the larger the amplitude of SLS is, the larger the amplitude of $S_{0}(E-P) / h$. This is a general trend however, and does not line up well on any straight line. In particular, the light line in Fig. 13 indicates the slope the data would have if SLS were simply related to $S_{0}(E-P) / h$ (see further discussion below). We find that for small $S_{0}(E-P) / h$ (less than $3 \times 10^{-8} \mathrm{~s}^{-1}$ ) the amplitude of SLS is larger than expected based on this simple relationship, and for large $S_{0}(E-P) / h$ the amplitude of SLS is often smaller than expected. Reverdin et al. (2007; their Fig. 11) show that generally less than $50 \%$ 


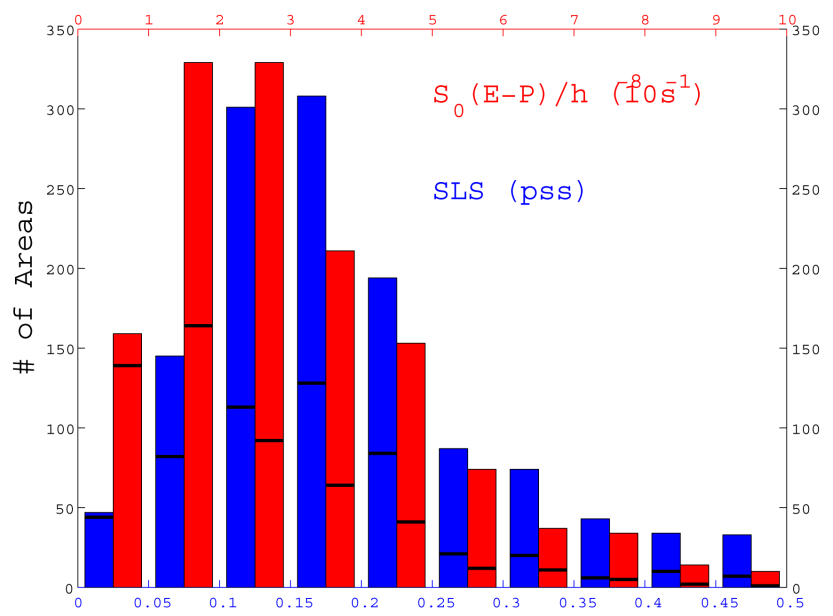

Fig. 8. Frequency distribution of the amplitude of SLS (blue bars) and $S_{0}(E-P) / h$ (red bars). The ordinate is the number of $2.5^{\circ} \times$ $2.5^{\circ}$ areas in the global ocean with amplitude in a given range. Units for the abscissa are given by red and blue text in the upper and lower parts of the figure. Black horizontal bars divide the number of areas in the Southern Hemisphere below the bars from the number in the Northern.

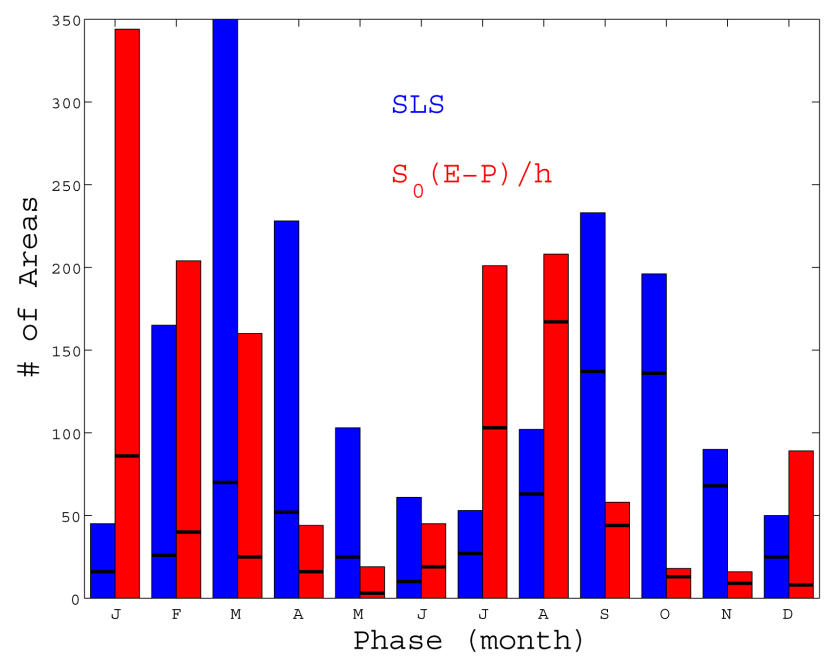

Fig. 9. As in Fig. 8, but for phase in months.

of the variance of the seasonal SLS in the tropical Atlantic can be explained by surface forcing consistent with the scatter in Fig. 13. By contrast, Yu (2011) shows that in some areas, surface forcing explains over $90 \%$ of the total variance of SLS. This balance is dominant under the ITCZ and along the western boundary of the North Pacific (Yu, 2011; Fig. 9). For the phase, there are two groupings of points in SLS, March-April (largely determined by Northern Hemisphere variability) and September-October (determined by the Southern Hemisphere). Note these groupings match the frequency distribution of Figs. 6 and 7. The light line indicates where points would line up if the SLS were 3 months
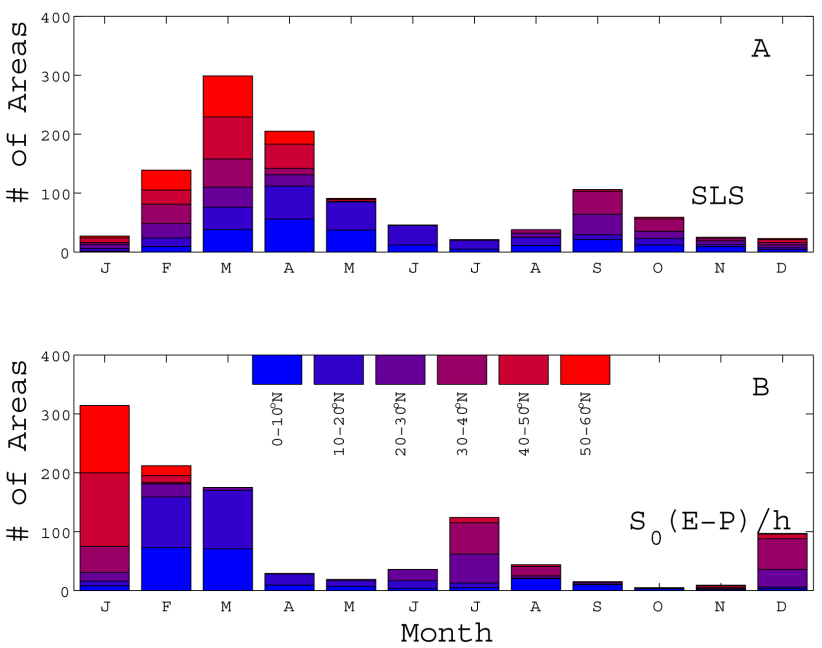

Fig. 10. (a) Frequency distribution of phase of SLS in the Northern Hemisphere only. Numbers on the y-axis represent a number of $2.5^{\circ} \times 2.5^{\circ}$ squares with a particular value. Different colors represent different latitude ranges, with a color scale shown at top of panel (b). (b) The same, but for $S_{0}(E-P) / h$ instead of SLS.

or $1 / 4$ cycle behind $S_{0}(E-P) / h$. Notice that the SLS maximum generally comes earlier than this $1 / 4$ cycle delay, in agreement with Reverdin et al. (2007) in the tropical Atlantic. In contrast, Chang (1993) has argued that, in the case of the mixed-layer heat budget, if the mixed-layer is thin, its adjustment to surface forcing should be nearly instantaneous. Perhaps the thickness of the mixed-layer is an important factor determining the phase delay between surface freshwater forcing and SLS.

A simplified form of the same information is presented as a frequency distribution of $S_{0}(E-P) / h$ amplitude (Fig. 8, red bars) and phase (Fig. 9, red bars), and for the Northern Hemisphere (Fig. 10b). We can see that this quantity in a global sense leads the SLS by 1-2 months (Fig. 9), with maxima in January and July/August. The red bars show the surface flux at a maximum during the period when the ocean is getting saltier (January and July) and a minimum when it is getting fresher (May and November). This is consistent with winter months being a time of maximum evaporation in the western boundary regions of the Northern oceans. This strong wintertime evaporation is associated with mode water formation (e.g., Oka and Qiu, 2011). The histogram of Fig. 9, and the phase distribution of Fig. 14 are controlled mainly by $E-P$. We did a similar calculation as shown by the red bars in Fig. 9 using only $E-P$ instead of $S_{0}(E-P) / h$. The results are similar, so are not displayed here, but with some interesting differences. The peaks of the red bars from Fig. 9 are a month or so later for just $E-P$.

Breaking Eq. (1) down, we suppose that SLS (or $S$ ) on the seasonal time scale does not depend on advection, or entrainment, and obeys this simple relationship between SLS 

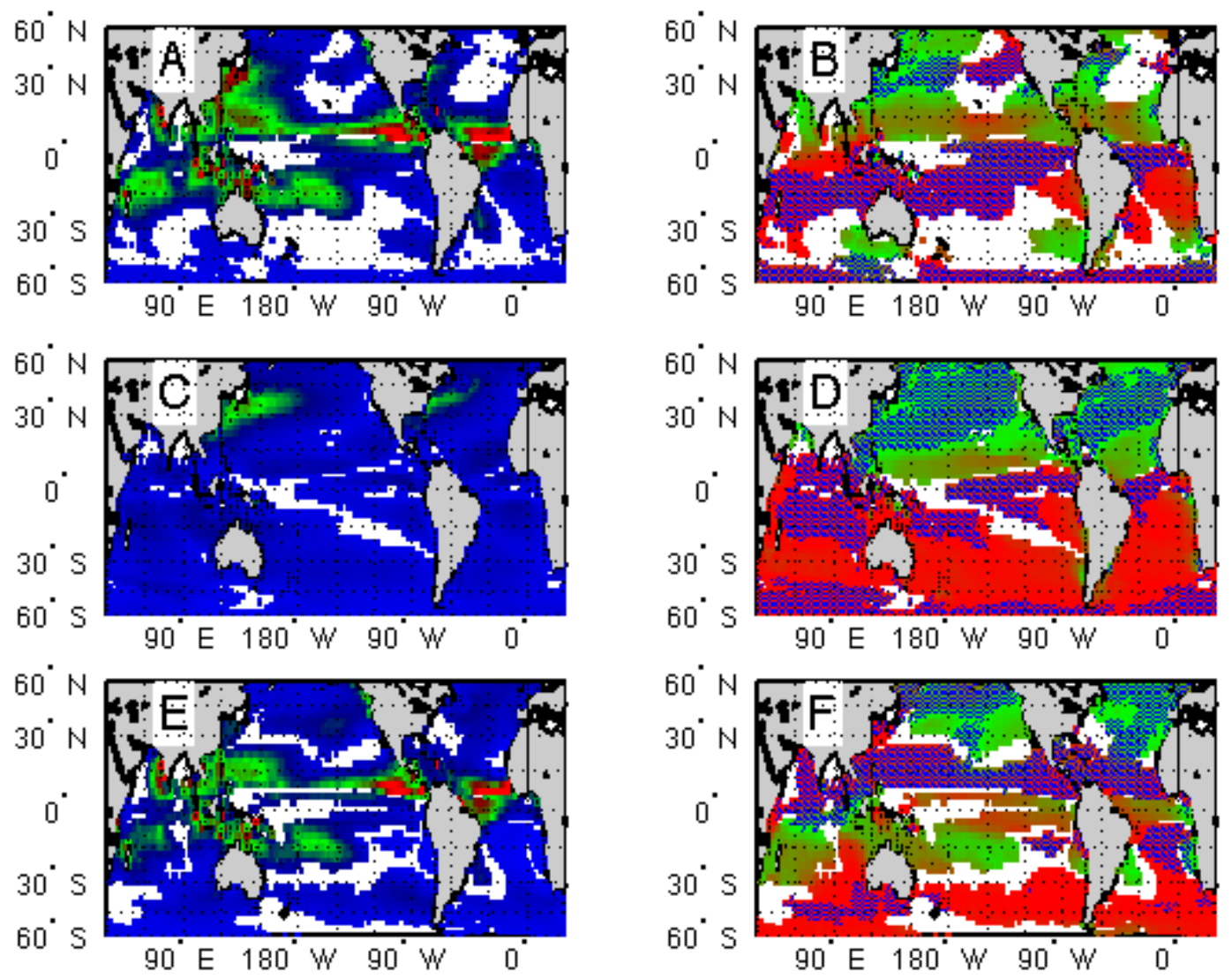

Fig. 11. Amplitude (left column) and phase (right column) of $E-P$ (top row), $E$ (middle row) and $P$ (bottom row). Amplitudes are in units of $10^{-4} \mathrm{~kg} \mathrm{~m}^{-2} \mathrm{~s}^{-1}$. Ocean areas with no color had sufficient observations but were found to have no statistically significant seasonal cycle.
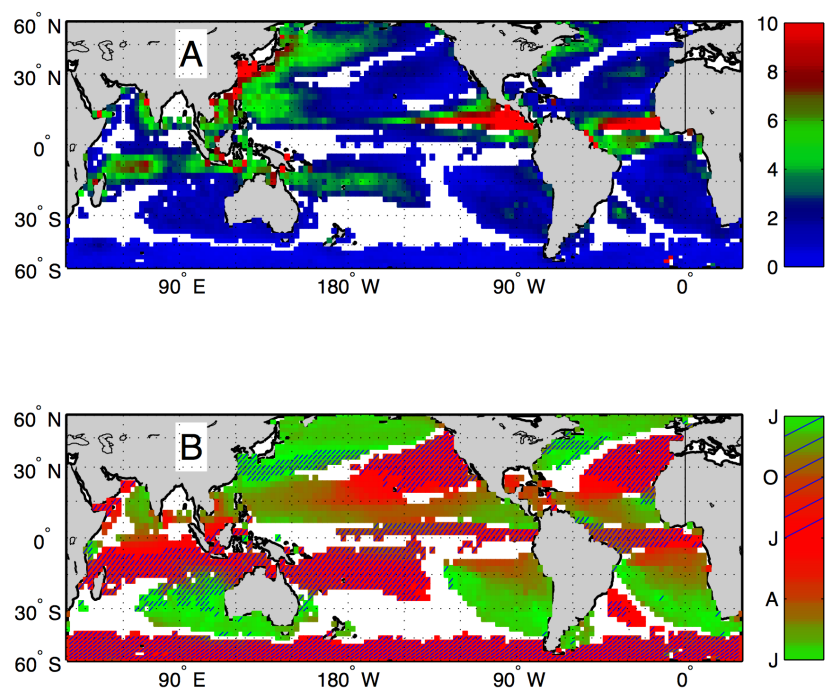

Fig. 12. Amplitude (top panel) and phase (bottom panel) of $S_{0}(E-$ $P) / h$. Amplitudes are in units of $10^{-8} \mathrm{~s}^{-1}$. Phases are in units of months. Ocean areas with no color had sufficient observations, but were found to have no statistically significant seasonal cycle using a standard statistical test. and surface forcing of freshwater:

$\frac{\partial S}{\partial t}=\frac{S_{0}(E-P)}{h}$.

To examine the seasonal component of this balance, let $S=$ $A \sin (\omega t+\phi)$, where

$\omega=2 \pi$ radians $\mathrm{yr}^{-1}=20 \times 10^{-8} \mathrm{~s}^{-1}$

and $\phi$ is some arbitrary phase. In that case, we have

$\frac{\partial S}{\partial t}=A \omega \cos (\omega t+\phi)=A \omega \sin \left(\omega t+\phi+\frac{\pi}{2}\right)$.

To make Eq. (2) balance, we need to have

$\frac{S_{0}(E-P)}{h}=B \sin \left(\omega t+\phi+\frac{\pi}{2}\right)$,

where $B$ is the amplitude of $S_{0}(E-P) / h$. The phase of $\frac{\pi}{2}$ represents a $1 / 4$ cycle or the three month delay between $S_{0}(E-P) / h$ and SLS that might be expected (Delcroix et al., 1996), as shown by the light line in Fig. 14. The frequency $\omega$ is the ratio of the amplitude of SLS and $S_{0}(E-$ $P) / h, B / A$. This is the factor represented by the light line in Fig. 13. The discrepancies between the scatter of points in 


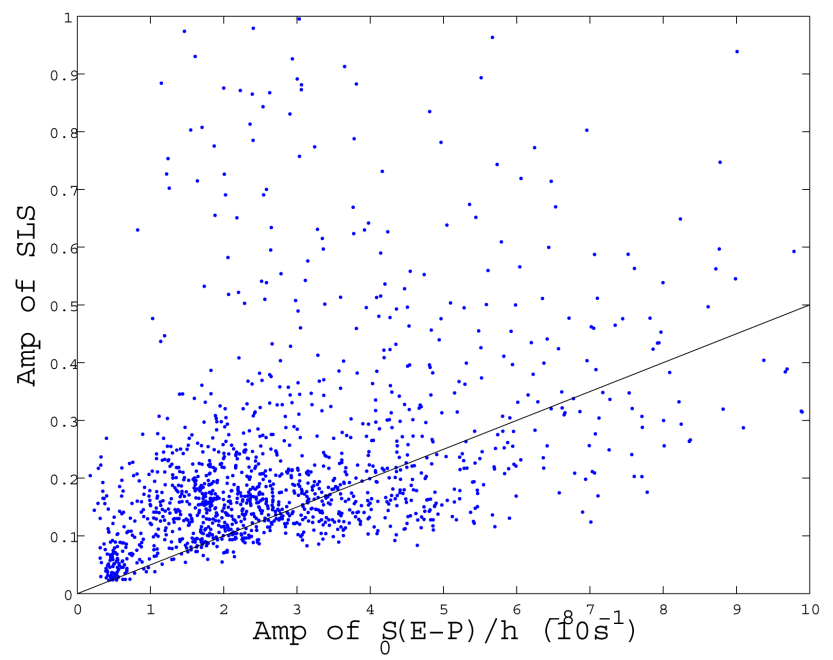

Fig. 13. Scatter plots comparing the amplitude of SLS (y-axis) and $S_{0}(E-P) / h$ (x-axis). Each dot represents a different $2.5^{\circ} \times 2.5^{\circ}$ area. Light line is as discussed in the text.

Figs. 13 and 14 and the light lines indicate that while surface forcing is an important element in producing the seasonal cycle of SLS, it is not the complete story. In most cases, the SLS maximum comes a month or two too early (the same scatter plots were made with just $E-P$, with similar results.) BFM looked at four examples of areas in the Pacific and compared $\mathrm{d} S / \mathrm{d} t$ with $S_{0}(E-P) / h$ (their Table 1). They found similar results showing that $\mathrm{d} S / \mathrm{d} t$ peaks about a month to two earlier than would be expected if completely balanced by $S_{0}(E-P) / h$ in three of the areas. What we have shown here is that this appears to be the case over much of the globe. These results agree with those of Mignot and Frankignoul (2003), who found about a 1 month lag between SLS and surface freshwater forcing. However, they were looking at a somewhat different quantity, the anomaly from the mean seasonal cycle, not the seasonal cycle itself. A similar result is that of $\mathrm{Yu}(2011$; Fig. 12) who found a 2-4 month covariance lag between mixed-layer salinity and surface freshwater forcing in the areas of the ocean where freshwater forcing is dominant. Finally, this result is similar to that of Delcroix et al. (1996). However, they found a 3 month delay as opposed to the 1-2 month delay found here. It is possible that part of the 1-2 month delay can be explained by vertical advection. In the Northern Hemisphere extratropics $S_{0}(E-P) / h$ peaks in boreal spring/summer, whereas vertical advection peaks in boreal winter/spring. Inclusion of the vertical advection term in the salinity balance would therefore tend to reduce the 1-2 month delay. However, there are large regions near the western boundaries and in the tropics where seasonal variations of vertical advection are insignificant and cannot explain the lag.

The average amplitude as a function of latitude (Fig. 15) compares SLS and $S_{0}(E-P) / h$ in a less detailed way. In

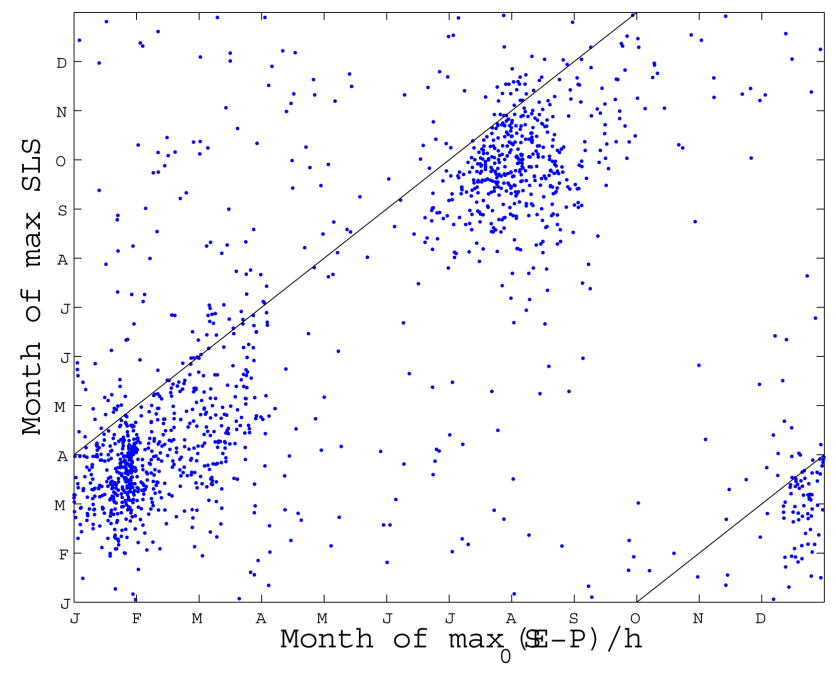

Fig. 14. Scatter plots comparing the phases of SLS (y-axis) and $S_{0}(E-P) / h$ (x-axis). Each dot represents a different $2.5^{\circ} \times 2.5^{\circ}$ area. The light line indicates a 3 month phase delay between $S_{0}(E-$ $P) / h$ and SLS.

this calculation, amplitudes were averaged in $10^{\circ}$ latitude bands. The highest amplitudes are just north of the equator, demonstrating the much more seasonal nature of the Northern Hemisphere. If Eq. (2) were true, one would expect the values from the red curve to fall on top of the blue curve given the scaling of the left and right axes. This is close to being the case for the Northern Hemisphere between 25 and $45^{\circ} \mathrm{N}$ and also for the Southern Hemisphere at 15 and $25^{\circ} \mathrm{S}$. When the two curves do not fall on top of each other and the blue curve is above the red curve, the SLS amplitude is too large to be driven by surface forcing alone.

We can take the difference between the amplitude of SLS and $S_{0}(E-P) / h$ to see where the two are out of balance and by how much (Fig. 16). Some caution should be used in looking at this figure. The calculation of the difference does not take into account individual errors in $E, P$, SLS or $h$. To some extent these errors are contained in the scatter used to calculate the variances that are used to do the statistical test for significance. However, because $h$ is a climatological value with no scatter, the significance is perhaps underestimated. With this caveat in mind, Fig. 16 shows that the imbalance is less than $5.0 \times 10^{-8} \mathrm{~s}^{-1}\left(0.1 \mathrm{month}^{-1}\right)$ over much of the globe. In much of the vast area of the North Pacific along the western and northern boundary dominated by evaporation, the figure shows that the difference between the terms is not statistically significant. It is borderline significant in the rest of the area. This is also the case in other areas, the eastern tropical Pacific, the eastern North Atlantic, and much of the South Pacific and South Atlantic. There are a few areas where the difference is statistically significant, and the amplitude of SLS is too large to be explained by $S_{0}(E-P) / h$ (blue color): (1) parts of the eastern tropical 


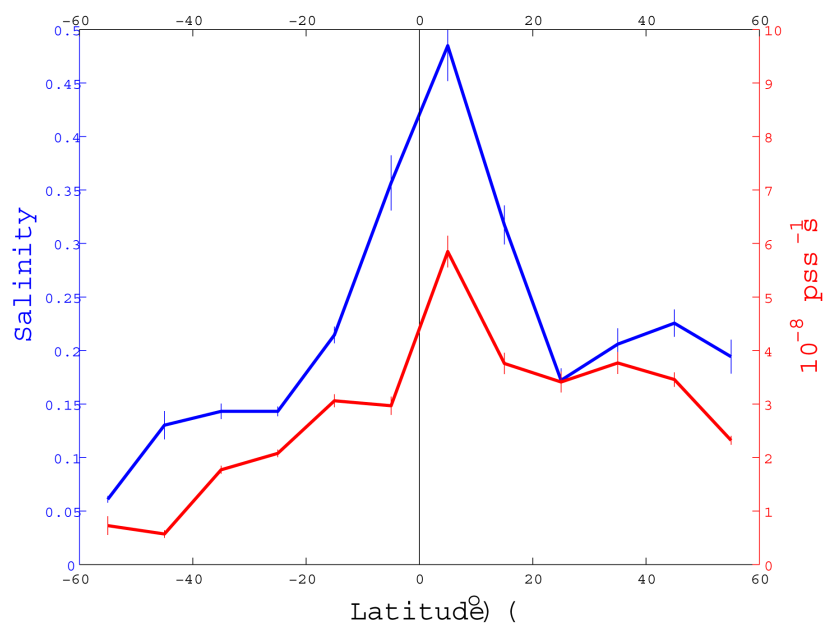

Fig. 15. Amplitude of SLS (blue line, left axis units) and $S_{0}(E-$ $P) / h$ (red line, right axis units) averaged in $10^{\circ}$ latitude bands. Error bars are standard error, i.e., standard deviation divided by the square root of the number of squares in each band.

Atlantic and Pacific, specifically the Gulf of Guinea and the coast of Ecuador; (2) the Arabian Sea; (3) Indonesian seas and South China Sea; (4) the coast of Labrador and entrance to the Labrador Sea; (5) the North Brazil coast; and (6) the central Pacific ITCZ. In (1), near Africa, this corresponds to the outflow of the Congo River, which could have some influence. Its discharge peaks twice per year, in March and October (Dai and Trenberth, 2002). Evidence of this influence can be seen in the horizontal advection term (Fig. 6a). In (2), the area corresponds to that documented by Rao and Sivakumar (2003), who attributed the large seasonal cycle there to advection during the summer monsoon season. For (3), perhaps continental or island runoff are the cause. In (4) the area is affected by freshwater export by the Labrador Current (Schmidt and Send, 2007; Straneo, 2006). This export peaks in summer, which matches the cycle of SLS, which peaks in wintertime. Along the north coast of Brazil, (5), the enhanced seasonal cycle is likely to be a result of seasonal changes in the northwestward advection of runoff from the Amazon River (Hellweger and Gordon, 2002; Foltz and McPhaden, 2008; Romanova et al., 2011), whose discharge peaks in May or June (Dai and Trenberth, 2002). Again this matches the SLS, which peaks in winter, and generally agrees with the magnitude and phasing of the horizontal advection term (Fig. 6). For the Pacific ITCZ, (6), BFM showed that seasonal advection of the mean salinity gradient was a statistically significant part of the seasonal SLS dynamics, where seasonally-varying zonal currents cross a meridionally sloping mean salinity gradient. There are areas where the SLS amplitude is too small to match $S_{0}(E-P) / h$ (red shading), near Central America and West Africa. This could be due to damping of the SLS signal by advection or entrainment.

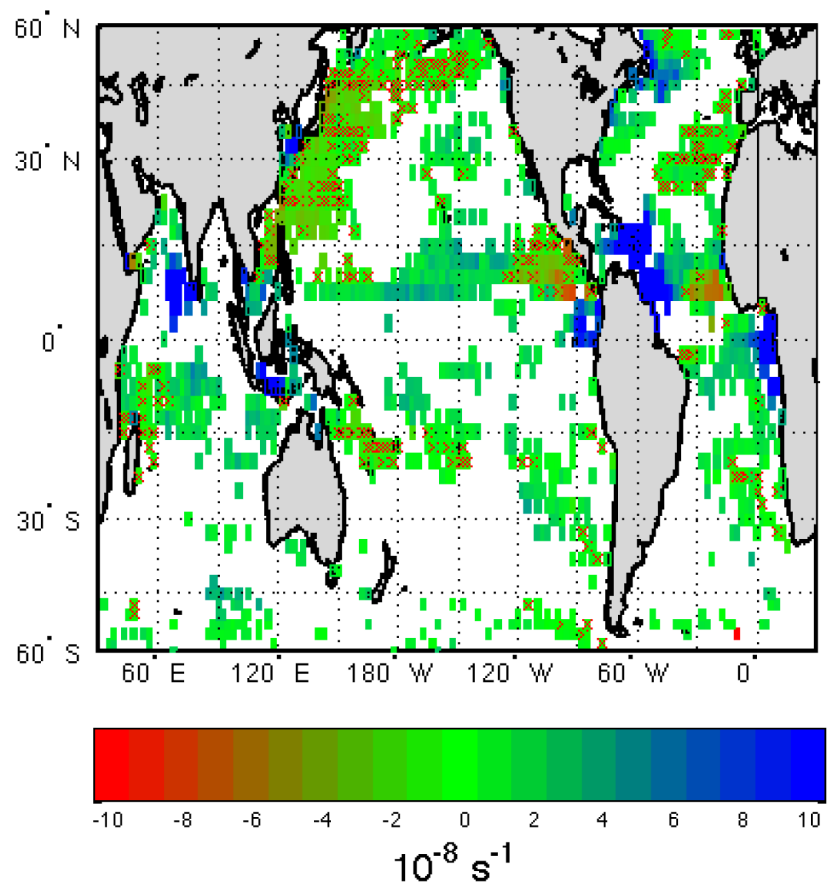

Fig. 16. Difference amplitude, namely omega*SLS amplitude minus $S_{0}(E-P) / h$ amplitude. Omega should be the lower-case greek version (looks like a curly w). A red " $\mathrm{x}$ " is overlaid on a $2.5^{\circ} \times 2.5^{\circ}$ square when the two quantities are not significantly different from each other.

We examined the $2.5^{\circ} \times 2.5^{\circ}$ squares where there were seasonal cycles of $S_{0}(E-P) / h$, but not SLS, that is, areas where there was atmospheric forcing with a seasonal component, but no corresponding seasonal variability in the ocean. In these squares, the amplitude of the surface forcing tended to be smaller than for squares with oceanic variability. The median value of amplitude of $S_{0}(E-P) / h$ for squares with no corresponding oceanic seasonal cycle is $1.3 \times 10^{-8} \mathrm{~s}^{-1}$. For squares with an oceanic seasonal cycle, the median value is $2.5 \times 10^{-8} \mathrm{~s}^{-1}$. This result suggests that the weaker the surface forcing, the less likely an area is to have a statistically significant seasonal cycle of SLS. This fits with the general picture of the seasonal variability of SLS being strongly related to $S_{0}(E-P) / h$.

\section{Discussion}

The frequency distribution of Fig. 9 implies a significant semi-annual transfer of water from ocean to atmosphere or horizontally within the ocean. Areas of the ocean that have a high salinity in March lose net freshwater between the months of September and March and gain freshwater between March and September (in the absence of other processes to alter SLS). Presumably this water leaving the ocean during the (northern) fall and winter moves somewhere else 
during that period. Perhaps it is transported to the atmosphere and land surface, or to some other part of the ocean.

To get a sense of how large that transfer might be, we can do a rough calculation. Suppose that the area with maximum salinity in March/April is comprised of $5002.5^{\circ} \times 2.5^{\circ}$ squares and that these squares experience a seasonal cycle of amplitude 0.19, the median value of SLS amplitudes (Fig. 13) (the mean value is 0.26). Also suppose that this occurs over a mixed-layer depth of typically $50 \mathrm{~m}$ and that a $2.5^{\circ} \times 2.5^{\circ}$ square has an area of $250^{2} \mathrm{~km}^{2}$. To go through a change of this magnitude, these squares would have to lose and gain an average amount of freshwater equivalent to $60 \mathrm{~cm}$ each year. Multiplying by the surface area, this comes out to a yearly transfer of freshwater of about $19 \times 10^{3} \mathrm{~km}^{3}$, larger than the total atmospheric content of about $13 \times 10^{3} \mathrm{~km}^{3}$ (Trenberth and Guillemot, 1994) and much larger than the seasonal cycle of water vapor content in the atmosphere which is about $1.0 \times 10^{3} \mathrm{~km}^{3}$ (Trenberth et al., 1988). For such a large ocean-atmosphere exchange of freshwater to occur, there must be a significant pathway for freshwater to get from one place to another during the course of a year, with the atmosphere being the obvious candidate. The frequency distribution of Fig. 9 and distribution map of Fig. 4 imply that this pathway leads from the Northern Hemisphere under the ITCZ and along the northern and western boundary of the North Pacific and North Atlantic, where SLS peaks in March, to the Southern Hemisphere and the eastern North Pacific and North Atlantic, where SLS peaks in September and October. The land surface also plays a part by storing water (Ramillien et al., 2005). The Northern Hemisphere atmosphere contains more moisture during the boreal summer months than in the winter due to higher temperature (Sun and Oort, 1995). This is consistent with atmospheric moisture transport from Southern to Northern Hemispheres during boreal summer.

The difference between the maxima in September and March from Fig. 9 implies that the ocean contains more mass during September than it does in March. This agrees with a study of net oceanic mass from satellite altimetry (Minster et al., 1999), which shows a maximum of oceanic mass in mid-September equivalent to $9.5 \mathrm{~mm}$ of sea level height above a minimum value, and a study of satellite gravity measurements (Chambers et al., 2004), which shows a maximum of oceanic mass in mid-October equivalent to $8.5 \mathrm{~mm}$ of sea level height. A $9.5 \mathrm{~mm}$ height difference is equivalent to a globalized average SLS amplitude of 0.02 when spread over a roughly average $50 \mathrm{~m}$ thick mixed-layer. Taking our median amplitude, 0.19 , and multiplying it by the $37 \%$ of the surface of the ocean between $60^{\circ} \mathrm{S}$ and $60^{\circ} \mathrm{N}$ that has a statistically significant SLS seasonal cycle, you get a globalized value of 0.06 , which has the same order of magnitude, though is somewhat larger. Note that by taking the mean amplitude, 0.26 , one gets a globalized value of 0.1 .

The results shown here indicate that the seasonal cycle of SLS is in most places in rough balance with input and export of freshwater at the ocean surface through evaporation and precipitation. A typical imbalance has a magnitude of less than $5.0 \times 10^{-8} \mathrm{~s}^{-1}$ (Fig. 16). This is the case throughout the evaporation-dominated regime of the mid-latitude North Pacific along the western and northern boundaries. Areas with larger imbalances than that correspond to places where one might expect them to exist, e.g., the vicinity of the Amazon River plume, the monsoon-influenced Arabian Sea and to a lesser extent the ITCZ.

This is not the complete picture though. Figure 13 indicates that the size of the seasonal cycle of SLS is in most places larger than would be expected by surface forcing alone. This mismatch is especially noticeable in the tropics (Figs. 10, 15 and 16) where horizontal advection plays a large role (Fig. 6). Perhaps this is also a component of vertical mixing as the top of the thermocline is eroded in winter or restratified in summer. In areas of the subtropical and tropical oceans equatorward of the great horizontal salinity maxima where the subtropical underwater outcrops (Bingham et al., 2002; O'Connor et al., 2002, 2005), salinity increases downward at the base of the mixed layer towards the shallow salinity maximum (Suga et al., 2000). So as the mixed layer increases in thickness during winter, saltier water is mixed into the surface layer. This is consistent with the prevalence of high salinity in the late winter seen in Fig. 9. This is not the case, however, poleward of the central horizontal salinity maxima where salinity decreases with depth. In that case, one would expect lower salinity in late winter as a result of entrainment of the underlying low salinity water. As the mixed-layer increases and decreases in size over the course of the year, it incorporates freshwater and/or salt from the layer below. This would be especially strong in areas of deep convection, formation areas of mode, intermediate or deep water. How much this might contribute to the seasonal signal of SLS and how this balance might work is a subject for future study. It is also possible that there are significant seasonal variations of $\mathrm{d} S / \mathrm{d} z$, which were not considered in this study. For example, Foltz and McPhaden (2008) found a large seasonal cycle of $\mathrm{d} S / \mathrm{d} z$ in the tropical North Atlantic associated with barrier layer formation.

The mystery that this analysis leaves us with is shown in Figs. 9 and 14, that is, the shortened phase delay between SLS and $S_{0}(E-P) / h$. Why does this delay seem to be $1-$ 2 months shorter than we would expect, consistent across ocean basins and regimes? A couple of possible explanations present themselves. We have done a harmonic analysis here, which assumes that the signal is in the form of a sine function. SLS is controlled by physical processes that do vary in a smooth, sinusoidal way. A full Fourier decomposition of the SLS might find semi-annual or bi-annual or other components that could skew the seasonal cycle, turning it into, say, a sawtooth-like form rather than a symmetric sine either for SLS or $S_{0}(E-P) / h$, or both. One could imagine this being the case for an area of the ocean that is subject to a 
single season of very intense rainfall with much less surface or other input of freshwater at other times of year.

Another possible explanation involves the idea that we have looked at SLS, that is, the near-surface salinity. There has been a lot of attention in recent years paid to barrier layers (Sato et al., 2004, 2007; de Boyer Montegut et al., 2004), low salinity layers that occupy the upper water column and inhibit vertical mixing (Lukas and Lindstrom, 1991). The presence of a barrier layer may shorten the time it takes the surface salinity to react to an impulsive atmospheric input of freshwater. So Figs. 9 and 14 may reflect the effect of barrier layers that shorten the response time of SLS to seasonal forcing. Whatever the explanation of this discrepancy, it is likely that the too large amplitudes and the too short phase delays (Figs. 8, 9, 13 and 14) are related.

A caveat associated with this discussion has to do with errors in measurement of evaporation, precipitation, mixedlayer depth and SLS. All of these measurements and their uncertainties are present in Figs. 8, 9, 13 and 14 in unknown amounts. To some extent, these uncertainties are reflected in the scatter of points in Fig. 14. We have examined a histogram of phase delays between SLS and $S_{0}(E-P) / h$ shown in Fig. 14 (not displayed). This clearly shows that the phase delay is less than three months and greater than 1, which can be easily surmised from Fig. 14.

We have shown that the advection and entrainment terms can be significant in some areas. The SLS could also be balanced by input of salt or freshwater to the surface layer at some other time scale, whether by advection, mixing, entrainment, surface $E-P$ forcing or some other process. As an example of such a time scale, El Niño events are phaselocked to the seasons and may produce variability of surface properties that, while seasonal in nature, are not produced by physical processes that are fundamentally seasonal. BFM did a similar calculation as shown in Fig. 3 controlling for the El Niño phase, and got similar results for the Pacific basin.

Another related issue is the intensification of the global hydrologic cycle in recent years. Hosoda et al. (2009) have shown that the hydrologic cycle has accelerated, making salty areas of the surface ocean saltier and fresh areas fresher (Durack and Wijffels, 2010). An intensifying hydrologic cycle also could mean changes in the seasonal cycle of SLS and freshwater flux. That is, there could be long-term variability in the strength and distribution of the seasonal cycles of these quantities. BFM did investigate the possibility of their results being sensitive to the ENSO cycle, and found little difference in results when examining the seasonal cycle only during El Niño or La Niña years. However, other types of climate variability, including long-term warming induced by human activity, could be affecting the seasonal cycle of SLS or surface flux of freshwater. There is a need to investigate whether the seasonal cycle of SLS is in fact changing. This may be possible in some limited areas of the tropical ocean where long-term observing ship datasets exist, or where mooring programs such as TAO have been operating for a decade or more.

There is another issue associated with the distribution of data. Before the Argo era (Fig. 2), most SLS data were collected in the Northern Hemisphere, or along heavily travelled volunteer observing ship routes (Delcroix and Henin, 1991). This bias is quite apparent in Fig. 1. The Argo program has changed this, so that the global distribution of SLS data has been much more uniform since about 2000 . So using preArgo data to determine the seasonal cycle would bias the results toward a more limited set of areas. This is a risk of using pre-Argo data. On the whole, though, we preferred to use the pre-Argo data as there is an abundance of it.

With the recent launches of Aquarius and SMOS, the seasonal patterns displayed here will be a crucial test of the validity of those datasets. The satellites should measure seasonal cycles of roughly the same amplitude, phase and distribution as shown in Figs. 3-5. The hope is that the satellite measurements will add much more detail to those pictures. BFM, for example, looked at horizontal advection of the mean SLS by the seasonally-varying current, but not advection of the seasonal SLS by the mean current. There is no way to reliably estimate the latter with currently available data. However, with the satellite measurements coming available, this should become possible. While the salinity balance of the upper ocean is still not well-understood, the contribution of advection and mixing to the balance, whether seasonal or otherwise, will become clearer as these new observations come online.

Acknowledgements. We appreciate the efforts of two anonymous reviewers whose input greatly improved the manuscript. The GOSUD surface data were collected in the framework of national programmes. They are aggregated and made freely available in the frame of the GOSUD Project: http://www.gosud.org. Argo data were collected and made freely available by the International Argo Project and the national initiatives that contribute to it (http://www.argo.net). Argo is a pilot programme of the Global Ocean Observing System. FMB was supported by NASA under grants NNX09AU70G and NNX11AE83G. MJM was supported by NOAA. PMEL contribution \#3776.

Edited by: S. Josey

\section{References}

Adler, R. F., Huffman, G. J., Chang, A., Ferraro, R., Xie, P., Janowiak, J., Rudolf, R., Schneider, U., Curtis, S., Bolvin, D., Gruber, A., Susskind, J., Arkin, A. and Nelkin, E.: The Version 2 Global Precipitation Climatology Project (GPCP) Monthly Precipitation Analysis (1979-Present), J. Hydrometeorol., 4, 11471167, 2003.

Antonov, J. I., Seidov, D., Boyer, T. P., Locarnini, R. A., Mishonov, A. V. and Garcia, H. E.: World Ocean Atlas 2009, Volume 2: Salinity, NOAA Atlas NESDIS 69, 184 pp., 2010. 
Bengtsson, L.: The Global Atmospheric Water Cycle, Environ. Res. Lett., 5, 025202, doi:10.1088/1748-9326/5/2/025202, 2010.

Berger, M., Camps, A., Font, J., Kerr, Y., Miller, J., Johannessen, J., Boutin, J., Drinkwater, M. R., Skou, N., Floury, N., Rast, M., Rebhan, H., and Attema, E.: Measuring Ocean Salinity with ESA's SMOS Mission, ESA Bull.-Eur. Space, 111, 113-121, 2002.

Bingham, F. and Lukas, R.: Seasonal Cycles of Temperature, Salinity and Dissolved Oxygen Observed in the Hawaii Ocean Timeseries, Deep-Sea Res. Pt. II, 43, 199-213, 1996.

Bingham, F. M., Suga, T., and Hanawa, K.: The Origin of Waters Observed along $137^{\circ}$ E, J. Geophys. Res., 107, 3073, doi:10.1029/2000jc000722, 2002.

Bingham, F. M., Foltz, G. R., and McPhaden, M. J.: Seasonal cycles of surface layer salinity in the Pacific Ocean, Ocean Sci., 6, 775787, doi:10.5194/os-6-775-2010, 2010.

Bonjean, F. and Lagerloef, G. S.: Diagnostic Model and Analysis of the Surface Currents in the Tropical Pacific Ocean, J. Phys. Oceanogr., 32, 2938-2954, 2002.

Boyer, T. P. and Levitus, S.: Harmonic Analysis of Climatological Sea Surface Salinity, J. Geophys. Res.-Oceans, 107, 8006, doi:10.1029/2001JC000829, 2002.

Boyer, T., Levitus, S., Antonov, J., Conkright, M., O’Brien, T., and Stephens, C.: World Ocean Atlas 1998 Volume 4: Salinity of the Atlantic Ocean, NOAA Atlas NESDIS 30, US Gov. Printing Office, Washington DC, 1998a.

Boyer, T., Levitus, S., Antonov, J., Conkright, M., O’Brien, T., and Stephens, C.: World Ocean Atlas 1998 Volume 5: Salinity of the Pacific Ocean, NOAA Atlas NESDIS 31, US Gov. Printing Office, Washington DC, 1998b.

Boyer, T., Levitus, S., Antonov, J., Conkright, M., O'Brien, T. and Stephens, C.: World Ocean Atlas 1998 Volume 6: Salinity of the Indian Ocean, NOAA Atlas NESDIS 32, US Gov. Printing Office, Washington DC, 1998c.

Chambers, D. P., Wahr, J., and Nerem, R. S.: Preliminary observations of global ocean mass variations with GRACE, Geophys. Res. Lett., 31, 13310, doi:10.1029/2004GL020461, 2004.

Chang, P.: Seasonal cycle of sea surface temperature and mixed layer heat budget in the tropical Pacific Ocean, Geophys. Res. Lett., 20, 2079-2082, doi:10.1029/93GL02374, 1993.

da Silva, A. A., Young, A. C., and Levitus, S.: Atlas of Surface Marine Data 1994, Vol. I, Algorithms and Procedures, NOAA Atlas, NESDIS 6, Washington DC, 1994.

Dai, A. and Trenberth, K. E.: Estimates of Freshwater Discharge from Continents: Latitudinal and Seasonal Variations, J. Hydrometeorol., 3, 660-687, 2002.

de Boyer Montégut, C., Madec, G., Fischer, A. S., Lazar, A., and Iudicone, D.: Mixed layer depth over the global ocean: An examination of profile data and a profile-based climatology, J. Geophys. Res., 109, C12003, doi:10.1029/2004JC002378, 2004.

Delcroix, T. and Henin, C.: Seasonal and interannual variations of sea surface salinity in the Tropical Pacific Ocean, J. Geophys. Res., 96, 22135-22150, 1991.

Delcroix, T., Henin, C., Porte, V., and Arkin, P.: Precipitation and Sea-surface Salinity in the Tropical Pacific, Deep-Sea Res. Pt. I, 43, 1123-1141, 1996.

Delcroix, T., McPhaden, M., Dessier, A., and Gouriou, Y.: Time and space scales for sea surface salinity in the tropical oceans, Deep-Sea Res., 52, 787-813, 2005.
Dessier, A. and Donguy, J. R.: The sea surface salinity in the Tropical Atlantic between 10 degree S and 30 degree N - seasonal and interannual variations (1977-1989), Deep-Sea Res. A, 41, 81-100, 1994.

Durack, P. J. and Wijffels, S.: Fifty-Year Trends in Global Ocean Salinities and Their Relationship to Broad-Scale Warming, J. Climate, 23, 4342, doi:10.1175/2010JCLI3377.1, 2010.

Emery, W. J. and Thomson, R. E.: Data Analysis Methods in Physical Oceanography, 2nd and revised Edn., Elsevier Science Ltd., Oxford, UK, 392-397, 2001.

Foltz, G. R. and McPhaden, M. J.: Seasonal Mixed Layer Salinity Balance of the Tropical North Atlantic Ocean, J. Geophys. Res. 113, C02013, doi:10.1029/2007JC004178, 2008.

Foltz, G. R., Grodsky, S. A., Carton, J. A., and McPhaden, M. J.: Seasonal salt budget of the northwestern tropical Atlantic Ocean along $38^{\circ} \mathrm{W}$, Jour. Geophys. Res.-Oceans, 109, C03052, doi:10.1029/2003JC002111, 2004.

Gouriou, Y. and Delcroix, T.: Seasonal and ENSO Variations of Sea Surface Salinity and Temperature in the South Pacific Convergence Zone during 1976-2000, J. Geophys. Res.-Oceans, 107, 8011, doi:10.1029/2001JC000830, 2002.

Hellweger, F. L. and Gordon, A.: Tracing Amazon River water into the Caribbean Sea, J. Mar. Res., 60, 537-549, 2002.

Henocq, C., Boutin, J., Petitcolin, F., Reverdin, G., Arnault, S., and Lattes, P.: Vertical Variability of Near-Surface Salinity in the tropical: Consequences for L-Band Radiometer Calibration and Validation, J. Atmos. Ocean. Tech., 27, 192-209, doi:10.1175/2009JTECHO670.1, 2009.

Hosoda, S., Suga, T., Shikama, N., and Mizuno, K.: Global Surface Layer Salinity Change Detected by Argo and Its Implication for Hydrological Cycle Intensification, J. Oceanogr., 65, 579-586, doi:10.1007/s10872-009-0049-1, 2009.

Johnson, E., Lagerloef, G. S., Gunn, J., and Bonjean, F.: Surface salinity advection in the tropical oceans compared with atmospheric freshwater forcing: A trial balance, J. Geophys. Res., 107, 8014, doi:10.1029/2001JC001122, 2002.

Johnson, D. R., Boyer, T. P., Garcia, H. E., Locarnini, R. A., Baranova, O. and Zweng, M. M.: World Ocean Database 2009 Documentation, NODC Internal Report 20, NOAA Printing Office, Silver Spring, MD, 175 pp., 2009.

Lagerloef, G. S., Colomb, F. R., Le Vine, D. M., Wentz, F., Yueh, S., Ruf, C., Lilly, J., Gunn, J., Chao, Y., deCharon, A., Feldman, G., and Swift, C.: The Aquarius/SAC-D Mission: Designed to Meet the Salinity Remote-sensing Challenge, Oceanogr., 20, 68-81, 2008.

Lukas, R. and Lindstrom, E.: The Mixed Layer of the Western Equatorial Pacific, J. Geophys. Res., 96, 3343-3357, 1991.

Mignot, J. and Frankignoul, C.: On the interannual variability of surface salinity in the Atlantic, Clim. Dynam., 20, 555-565, doi:10.1007/s00382-002-0294-0, 2003.

Minster, J. F., Ceznave, A., Serafini, Y. V., Mercier, F., Gennero, M. C., and Rogel, P.: Annual cycle in mean sea level from Topex-Poseidon and ERS-1: inference on the global hydrological cycle, Global Planet. Change, 20, 57-66, doi:10.1016/S09218181(98)00058-7, 1999.

O'Connor, B. M., Fine, R., Maillet, K. A., and Olson, D. B.: Formation rates of subtropical underwater in the Pacific Ocean, DeepSea Res. Pt. I, 49, 1571, doi:10.1016/S0967-0637(02)00087-0, 2002. 
O'Connor, B. M., Fine, R., and Olson, D.: A global comparison of subtropical underwater formation rates, Deep-Sea Res. Pt. I, 1569-1590, 1569, doi:10.1016/j.dsr.2005.01.011, 2005.

Oka, E. and Qiu, B.: Progress of North Pacific Mode Water Research in the Past Decade, J. Oceanogr., 68, 5-20, doi:10.1007/s10872-011-0032-5, 2011.

Ramillien, G., Frappart, F., Ceznave, A., and Gunter, A.: Time variations of land water storage from an inversion of 2 years of GRACE geoids, Earth Planet. Sc. Lett., 235, 283, doi:10.1016/j.epsl.2005.04.005, 2005.

Rao, R. R. and Sivakumar, R.: Seasonal variability of sea surface salinity and salt budget of the mixed layer of the north Indian Ocean, J. Geophys. Res.-Oceans, 108, 3009, doi:10.1029/2001JC000907, 2003.

Ren, L. and Riser, S.: Seasonal salt budget in the northeast Pacific Ocean, J. Geophys. Res.-Oceans, 114, C12004, doi:10.1029/2009JC005307, 2009.

Reverdin, G., Kestenare, E., Frankignoul, C., and Delcroix, T.: Surface salinity in the Atlantic Ocean $\left(30^{\circ} \mathrm{S}-50^{\circ} \mathrm{N}\right)$, Prog. Oceanogr., 73, 311-340, 2007.

Roemmich, D. and Gilson, J.: The 2004-2008 mean and annual cycle of temperature, salinity, and steric height in the global ocean from the Argo Program, Prog. Oceanogr., 82, 81, doi:10.1016/j.pocean.2009.03.004, 2009.

Romanova, V., Köhl, A., and Stammer, D.: Seasonal cycle of near-surface freshwater budget in the western tropical Atlantic, J. Geophys. Res.-Oceans, 116, C07009, doi:10.1029/2010JC006650, 2011.

Saha, S., Moorthi, S., Pan, H., Wu, X., Wang, J., Nadiga, S., Tripp, P., Kistler, R., Woollen, J., Behringer, D., Liu, H., Stokes, D., Grumbine, R., Gayno, G., Wang, J., Hou, Y., Chuang, H., Juang, H. H., Sela, J., Iredell, M., Treadon, R., Kleist, D., Van Delst, P., Keyser, D., Derber, J., Ek, M., Meng, J., Wei, H., Yang, R., Lord, S., Van, D. D., Kumar, A., Wang, W., Long, C., Chelliah, M., Xue, Y., Huang, B., Schemm, J., Ebisuzaki, W., Lin, R., Xie, P., Chen, M., Zhou, S., Higgins, W., Zou, C., Liu, Q., Chen, Y., Han, Y., Cucurull, L., Reynolds, R. W., Rutledge, G., and Goldberg, M.: The NCEP Climate Forecast System Reanalysis, B. Am. Meteorol. Soc., 91, 1015-1057, 2010.

Sato, K., Suga, T., and Hanawa, K.: Barrier layer in the North Pacific subtropical gyre, Geophys. Res. Lett., 31, 5301, doi:10.1029/2003GL018590, 2004.
Sato, K., Suga, T., and Hanawa, K.: Barrier layers in the subtropical gyres of the world's oceans, Geophys. Res. Lett., 33, L08603, doi:10.1029/2005GL025631, 2007.

Schmidt, S. and Send, U.: Origin and Composition of Seasonal Labrador Sea Freshwater, J. Phys. Oceanogr., 37, 1445-1454, 2007.

Straneo, F.: Heat and Freshwater Transport through the Central Labrador Sea, J. Phys. Oceanogr., 36, 606-628, 2006.

Suga, T., Kato, A., and Hanawa, K.: North Pacific Tropical Water: its climatology and temporal changes associated with the climate regime shift in the 1970s, Prog. Oceanogr., 47, 223-256, 2000.

Sun, D. and Oort, A. H.: Humidity-temperature Relationships in the Tropical Troposphere, J. Climate, 8, 1974-1987, 1995.

Tomczak, M.: Salinity Variability in the Surface Layer of the Tropical Western Pacific Ocean, J. Geophys. Res., 100, 20499-20515, 1995.

Trenberth, K. E. and Guillemot, C. J.: The total mass of the atmosphere, J. Geophys. Res.-Atmos., 99, 23079-23088, doi:10.1029/94JD02043, 1994.

Trenberth, K. E., Christy, J. R., and Olson, J. G.: Global Atmospheric Mass, Surface Pressure, and Water Vapor Variations, J. Geophys. Res.-Atmos., 92, 14815, doi:10.1029/JD093iD09p10925, 1988.

UNESCO: Tenth Report of the Joint Panel on Oceanographic Tables and Standards, Unesco Technical Papers in Marine Science, Paris, 36, 25 pp., 1981.

Valladares, J., Fennel, W., and Morozov, E.: Replacement of EOS80 with the International Thermodynamic Equation of Seawater - 2010 (TEOS-10), Deep-Sea Res. Pt. I, 58, p. 978, doi:10.1016/j.dsr.2011.07.005, 2011.

Yu, L.: On Sea Surface Salinity Skin Effect Induced by Evaporation and Implications for Remote Sensing of Ocean Salinity, J. Phys. Oceanogr., 40, 85-102, doi:10.1175/2009JPO4168.1, 2010.

Yu, L.: A global relationship between the ocean water cycle and near-surface salinity, J. Geophys. Res.-Oceans, 116, C10025, doi:10.1029/2010JC006937, 2011.

Yu, L., Jin, X., and Weller, R.: Multidecade Global Flux Datasets from the Objectively Analyzed Air-sea Fluxes (OAFlux) Project: Latent and Sensible Heat Fluxes, Ocean Evaporation, and Related Surface Meteorological Variables, Woods Hole Oceanographic Institution, OA Flux Project Tech Rept. OA-2008-01, Woods Hole, MA, 64 pp., 2008. 